\title{
Centralisation: placing Peer Assisted Study Sessions (PASS) within the wider work of learning developers
}

\section{Maxinne Connolly-Panagopoulos}

University of Glasgow, UK

\section{Abstract}

This article investigated whether a centralised PASS system, run in partnership between academic leads (ALs) and learning developers (LDs), might be supported by staff and students currently involved in PASS ( $\mathrm{N}=11)$ within a Higher Education Institution (HEI). The study interviewed staff from the humanities, physical science, medical science, and the arts. Findings revealed that all participants were in favour of some form of centralisation. Centralised training of PASS mentors, advertising, and quality control received the strongest support. Based on these findings, the article argues that if LDs work closely with ALs centralisation is a viable solution to common challenges to PASS - such as low attendance, misconceptions about PASS, administrative costs, and scheme maintenance.

Keywords: Peer Assisted Study Sessions; peer assisted learning; learning developers; supplemental instruction.

\section{Introduction}

Peer Assisted Study Sessions (PASS), commonly found in Higher Education Institutions (HEls), aim to support learning and integration within a specific programme of study by providing a space for active discussion and cooperative learning between students (Capstick, 2004). Traditionally, PASS often focus on discussion or activities around academic course work. However, sessions might also include pastoral discussions (Green, 2011), or include one-to-one sessions (Mclntosh, 2019). PASS sessions are most often offered to first- and second-year students and facilitated by pairs of second- or third-year students, referred to as 'PASS mentors' (Garcia-Melgar et al., 2021) or 'leaders' in some 
literature (Rapley, 2011; Mclntosh, 2019). PASS may also include support from students within the same year group (Hammond et al., 2010). While PASS is most often located and managed within specific subjects, this article will outline the benefits of centrally managed PASS schemes in higher education. The benefit of a PASS scheme that is codeveloped by learning developers and faculty academics is the inclusion of expert knowledge from learning developers in training PASS mentors to facilitate sessions. This article argues that the unique position of the learning developer within HEls also presents an opportunity for greater exposure of the wider student body to the benefits of PASS.

\section{Benefits of PASS}

PASS Initiatives have been associated with higher pass rates and attainment (Dawson et al., 2014; Herrmann-Werner et al., 2017), increased subject knowledge (Hammond, et al., 2010), and retention in historically challenging courses, especially within STEM (Congos and Schoeps,1998; Dawson et al., 2014; Herrmann-Werner et al., 2017; Fredrikkson et al., 2020). According to Herrmann-Werner (2017), due to the scholarly evidence of the benefits of PASS, it has become an integral part of medical courses in Germany. Fostier and Carey (2007) indicate that offering PASS on a biomedical cohort produced a marked positive effect on both exam scores and student retention. Similarly, Green (2018) reported that within a nursing cohort, $90 \%$ of students who engaged with PASS displayed an increase in subject knowledge. PASS attendance as a predictor of higher academic attainment was substantiated by Spedding, Hawkes and Burgess (2017) who found a positive relationship between PASS attendance and academic performance among 340 first-year psychology students. This positive correlation is perhaps a result of the active learning which we know PASS permits; according to Capstick (2004) and Garcia-Melgar et al. (2021) peer discussion of course material moves learning from a grade-focused, and perhaps a more surface learning position, to a position which focuses on deeper learning through the creation of meaning from the course content.

By being peer led, PASS sessions allow students to learn in an informal and supplementary environment; this encourages deeper knowledge and a greater sense of belonging and ownership among student cohorts (Hoffman et al., 2002; TibinganaAhimbisibwe et al., 2020; Garcia-Melgar et al., 2021) as well as increased communication and cohesion between students in the higher year(s) (Green, 2001; Dawson, et al., 2014). 
PASS is particularly beneficial to students from economically or socially disadvantaged communities as well as undergraduate and postgraduate international students, aiding both learning and integration (Rapley, 2011; Zaccagnini and Verenikina, 2013; Duah, Croft and Inglis, 2014; Chilvers, 2016). PASS schemes create a highly social and interactive learning environment that encourages the establishment of relationships with domestic and other international students feeling increased confidence, a greater sense of community, and ownership and learner cohesion (Zaccagnini and Verenikina, 2013; Higgins et al., 2019; Tibingana-Ahimbisibwe et al., 2020).

The benefits of participation in PASS also extend to mentors, who are able to develop transferable skills and in turn increase their employability (Smith, May and Burke, 2007). The benefits to the mentors also include developed academic knowledge as they are able to review and strengthen their understanding of course material through facilitation (Ody and Carey, 2009; Herrmann-Werner et al., 2017). In addition, among a cohort of medical students, Tamachi et al. (2018) found mentors reporting greater camaraderie, shared purpose, and social cohesion through their involvement as mentors. This finding points to the social benefits of PASS, as well as highlighting the implications for developing feelings of institutional belonging. Furthermore, academics benefit from PASS as they can adjust their courses in direct response to consistent feedback from mentors (Green, 2001; Rapley, 2011).

\section{Challenges of PASS}

Despite its many benefits, PASS schemes often experience low attendance (Allen, et al., 2019). With the exception of the sciences where engagement rates are higher (Draper, 2011), scholars have reported low attendance as a major challenge to the success and stability of PASS (Capstick, 2004; Green, 2011; Hammond, et al., 2010). Low attendance may be due to several practical issues such as timetable clashes and demanding course loads (Meertens, 2016). Additionally, Allen et al. (2019) found that low attendance was also due to incorrect perceptions that PASS was only for students who were failing. Stable attendance is vital for the success of PASS due to the central aspect of supplemental instruction which involves co-learning and discussion with peers (Fredrikkson et al., 2020). For a scheme to be effective, it is recommended to run weekly sessions that are routine and well planned with time for activities as well as questions and discussion (HerrmannWerner et al., 2017; PASS National Centre, 2018). 
Academic leads are also often responsible for the recruitment and training of PASS mentors (Glynn et al., 2006; Tibingana-Ahimbisibwe et al., 2020). Hermann-Werner et al. (2017) find that while supplemental instruction may reduce time demands on faculty, the task of recruiting and training mentors to ensure high quality schemes often led to more, rather than less, demand on AL time. This not only adds to the demands of PASS but might also lead to instances where mentors are not adequately trained in the skills necessary for the facilitation and running of a PASS (Herrmann-Werner et al., 2017; Garcia-Melgar et al., 2021). Mentors who are not adequately trained also run the risk of not knowing when to assert boundaries between facilitation and teaching. In some cases, this has led to programmes which are perceived as exam support or proof-reading services (Garcia-Melgar et al., 2021). Difficulty in securing funding to support the development of PASS has also been reported as a challenge to developing and maintaining PASS (Green, 2011). Institutional funding is aligned with strategic drives which are, in turn, often informed by quantitative measures such as academic attainment; PASS may be overlooked in favour of other academic initiatives (Ashwin, 2002). Despite evidence for a correlation between PASS and improved academic attainment (i.e.: Spedding, Hawkes and Burgess, 2017), it is difficult to ascertain why funding for PASS is a challenge. Perhaps more institution-specific results are needed to justify funding. As a result of a lack of funding, many PASS initiatives are unable to receive financial support which might ensure their success.

\section{Context of research}

The research for this paper was conducted in a HEl where the model of PASS described above was dominant. PASS was concentrated in disparate 'pockets' of the university - a large Russell group institution in Scotland - and was coordinated in these various departments by academic leads (ALs). The premise for research was the lack of communication between LDs and ALs championing PASS. Moreover, ALs were not aware of, or in contact with other academics working on PASS. This meant that within a single institution, there was considerable inconsistency in the delivery of PASS and a lack of resources and support for ALs. According to Ody and Carey (2013), flexibility is a positive feature of PASS. However, in the institution under discussion here, inconsistency made the development and promotion of a culture of peer-to-peer academic support challenging. 
It is the growth of this culture which, according to Black and MacKenzie (2008), is vital to the success of a PASS.

With these practitioner observations as a starting point, I conducted a deeper appraisal of PASS within the institution and proposed that schools move from developing PASS in a subject vacuum, to working in partnership with learning developers (LDs) to co-create and share responsibility for the implementation and maintenance of PASS. This concept, which will be referred to as the centralisation of PASS, appears in other institutions such as the University of Exeter's centralised Study Zone (2021), the University of Plymouth (2021), and the University of Bournemouth (2021). Centralisation is hardly novel and has achieved institutional success (Capstick, 2004) and yet is not routinely organised within HEls which may be due to varying organisations of LDs within institutions.

\section{Centralisation}

This research proposes that schemes which are co-created and shared between LDs and ALs could be beneficial in mitigating challenges to creating and maintaining PASS through a process of shared ownership. By sharing ownership of PASS, LDs would have an active involvement in setting up and maintaining the schemes, thus addressing the issue of the demands of time and resources in setting up a PASS. Another issue affecting the success of PASS is staff turnover. In some instances, one staff member is highly involved in PASS, and in the event of them leaving, the scheme crumbles. Continued co-partnership between ALs and teams of LDs would lead to sustained academic involvement in the running and maintenance of classes which, according to Green (2011), is vital for the longevity of PASS. Additional funding would also alleviate some of the start-up costs associated with PASS. Therefore, LDs would be encouraged to engage in scholarship on PASS to support funding bids.

Due to their specialist knowledge of learning and development, as well as their frequent contact with a variety of students, LD practitioners often have a 'birds eye view' of an institution. By becoming co-owners of PASS, through centralisation, LDs would be able to advise on how best to run and maintain PASS. They would also provide an area for staff and mentors to receive support for training, establishing, and maintaining PASS. Training is particularly vital for developing positive perceptions of PASS among staff and students. The LDs would work closely with faculty colleagues to train the mentors in facilitation, as 
well as to ensure quality control and that the scheme was successfully addressing the needs of the subjects. As LDs are accustomed to teaching across an institution, rather than within a specific subject area, they are likely to hold the skills necessary for engaging groups of students in a non-subject-specific scenario. Thus, LDs are well placed for passing their unique skills onto mentors. Therefore, by placing PASS within the wider work of LDs, an institution might see a co-ownership of PASS and greater benefits to both staff and students.

\section{Methodology}

As outlined above, the broader context of this study is a longer-term research project which appraised the varieties of PASS within the researcher's Scottish HEI. The present research involved an investigation of the institutional website, conversations with academics who had published on PASS or been cited as being involved in PASS, and a literature search to determine the number of active PASS schemes within the institution. This process was followed by semi-structured interviews and a focus group.

\section{Participants and procedure}

The study included 11 participants. Six were academic staff involved in a PASS within the humanities (1), medical (2) and physical sciences (3), and arts (4). Five, who formed the focus group, were student PASS mentors. One student, from humanities (1), who could not attend the focus group sent the researcher a personal statement regarding their experiences of PASS. All identifiable information has been removed and, where named, participants have been given pseudonyms and referred to as Academic Lead $(A L)$ for those who were interviewed and PASS Mentor for student mentors who participated in the focus group.

The interview and focus group questions explored the structure and content of each PASS, the department's approach to recruitment, training, and remuneration, overall attendance at sessions, challenges faced by $A L s$, the role of $A L s$, and finally a response to the idea of centralisation or the moving of PASS to co-ownership between ALs and LDs. Questions were guided by the scholarly literature which outlines the challenges to PASS, as well as the researcher's aim of appraising PASS and responses to centralisation within 
their institution. The focus of these questions informed the broad topics, which were later used to inform thematic clusters. For clarity in questioning, all participants were asked 'what are your thoughts on the movement towards a centralised PASS which would be developed and maintained alongside the team ${ }^{1}$. When asked to elaborate on centralisation, I made it clear that centralisation was not merely an instance where LDs took control of all administrative tasks but were actively involved in the development of schemes as partners who are knowledgeable in student learning and enhancement. Interviews and focus group were later transcribed and analysed using NVivo V.11. Using Braun and Clarke's (2006) thematic analysis as a guide, the interview and focus group questions formed the broad themes upon which data was clustered. Themes were populated to ensure that the varieties of PASS within the institution were represented.

\section{Results}

A summary of the full research findings relating to thematic clusters is presented in table.

1. The research found that all four PASS schemes were academic with pastoral discussions reported as a by-product of the scheme. Attendance was variable in the humanities (1) and physical sciences (3) who held their PASS on an informal and drop-in basis. The medical sciences (2) and arts (4) had timetabled sessions and reported better attendance and student involvement overall. All schemes recruited mentors internally via informal announcements or circulated posts. All mentors were trained by staff except in (3) who received no training. Mentors from (2) and (3) were unpaid, while those from (1) and (4) were paid. Most schemes indicated little staff involvement and appeared to be studentled. However, the clinical-based PASS within the medical sciences (2) reported high staff involvement.

All staff indicated a preference for a centralised PASS scheme, but with varied degrees of involvement from LDs. The main concern over centralisation was that the subjects would lose ownership over the content of PASS sessions. The medical sciences (2) expressed the least interest in a centralised PASS, due to the clinical nature of the scheme and the course being offered away from the main campus. However, staff expressed an interest in acquiring formal validation for mentors via a centralised PASS initiative such as the

\footnotetext{
1 Pseudonym 
academic development services. Other participants were in favour of a centralised PASS initiative in order to gain support in recruitment and training of mentors, and quality assurance. The results indicate that, despite concerns from all ALs and the focus group over schools maintaining ownership, centralisation appeared to be well-supported. A discussion of the findings in their entirety is outside of the scope of this piece. Instead, this article will focus on the themes which most closely speak to developing a case for the coownership of PASS schemes by LDs and academic departments. These themes are attendance, academic involvement, mentor recruitment, training and remuneration, and centralisation.

Table 1 shows the features of each subject's PASS. The findings indicate the variance between the structure of the PASS, with1, 2, and 4 being highly structured and 3 drop-in. In relation to content, 1-4 were set up to be academic in content, but did boast pastoral aspects. Attendance varied overall, with the most consistent attendance shown in 2 and 4, both of which were timetabled. All schemes recruited internally: 2 and 4 paid their mentors, while 1 and 3 did not. All except 2 had minimal academic involvement in the sessions. 1, 3, and 4 were in favour of a centralised system, with 2 being cautious due to the clinical aspect of the PASS.

Table 1. Overview of the research findings related to each of the 4 major themes.

\begin{tabular}{|c|c|c|c|c|c|}
\hline Area & PASS Structure \& content & Advertising \& attendance & $\begin{array}{l}\text { Mentor Recruitment, } \\
\text { Training \& Remuneration }\end{array}$ & Academic involvement & $\begin{array}{l}\text { Response to a } \\
\text { Centralised PASS }\end{array}$ \\
\hline 1. Humanities & $\begin{array}{l}\text { Fortnightly drop in } \\
\text { Academic and pastoral } \\
\text { Mentors develop material }\end{array}$ & $\begin{array}{l}\text { Advertised online, with posters } \\
\text { and academic shout out during } \\
\text { lectures. } \\
\text { Attendance varies 2- } 20\end{array}$ & $\begin{array}{l}10 \text { facilitators recruited } \\
\text { internally. } \\
\text { 1-day, intensive training } \\
\text { Paid hourly - living wage }\end{array}$ & $\begin{array}{l}\text { Minimal academic involvement } \\
\text { Meet informally and sporadically } \\
\text { with mentors. }\end{array}$ & $\begin{array}{l}\text { Yes } \\
\text { Support in administration, training and } \\
\text { advertising with retained departmental } \\
\text { discretion. }\end{array}$ \\
\hline $\begin{array}{l}\text { 2. Medical } \\
\text { Sciences }\end{array}$ & $\begin{array}{l}\text { Highly structured. } \\
\text { Practical, academic } \\
\text { exercises. } \\
\text { Conducted in a clinical } \\
\text { setting. }\end{array}$ & $\begin{array}{l}\text { Timetabled } \\
\text { Students are allocated a } \\
\text { session }\end{array}$ & $\begin{array}{l}\text { Self-selected } \\
\text { Trained by staff } \\
\text { Unpaid mentors }\end{array}$ & $\begin{array}{l}\text { High academic involvement } \\
\text { Mentors meet informally. }\end{array}$ & $\begin{array}{l}\text { No } \\
\text { Due to clinical focus. } \\
\text { Would like a centralised to provide some } \\
\text { external teaching validation for facilitators } \\
\text { i.e.: RET. }\end{array}$ \\
\hline $\begin{array}{l}\text { 3. Physical } \\
\text { Science }\end{array}$ & $\begin{array}{l}\text { Informal weekly drop-in } \\
\text { Academic providing support } \\
\text { for statistics software. }\end{array}$ & $\begin{array}{l}\text { Advertise online (Facebook, } \\
\text { Moodle \& email) } \\
\text { Attendance varies from 0-20 }\end{array}$ & $\begin{array}{l}\text { Internally recruited } \\
\text { Voluntary and unpaid. }\end{array}$ & $\begin{array}{l}\text { Academic staff not involved. } \\
\text { Mentors communicate via } \\
\text { Facebook. } \\
\text { Aimed to meet weekly but this } \\
\text { was not accomplished. }\end{array}$ & $\begin{array}{l}\text { Yes } \\
\text { Quality assurance, recruitment and } \\
\text { training from a centralised PASS would } \\
\text { benefit school. } \\
\text { Would want to maintain subject } \\
\text { ownership. }\end{array}$ \\
\hline 4. Arts & $\begin{array}{l}\text { Highly structured lab } \\
\text { sessions. } \\
\text { Theory and practice } \\
\text { Some pastoral advice. }\end{array}$ & $\begin{array}{l}\text { Sessions are timetabled } \\
\text { Average attendance of } 15 \\
\text { students }\end{array}$ & $\begin{array}{l}7-103^{\text {rd }} \text { year students recruited } \\
\text { Mentors are invited to complete } \\
\text { RETAF as part of facilitation. } \\
\text { Paid from GTA budget. }\end{array}$ & $\begin{array}{l}\text { Staff involvement is fractured. } \\
\text { Mentors meet for } 1 \text { hour once a } \\
\text { week to discuss PASS. }\end{array}$ & $\begin{array}{l}\text { Yes } \\
\text { Training of facilitators and encouraging } \\
\text { communication among leaders from a } \\
\text { centralised PASS would benefit. } \\
\text { Keep departmental involvement while } \\
\text { drawing from a centralised facility. }\end{array}$ \\
\hline
\end{tabular}


The results presented below are focussed on the question of centralisation in order to shed further light on the benefits of involving learning developers in the development and maintenance of PASS schemes in co-ownership with subject academics. This section will also highlight some of the variances in vital aspects of PASS such as the training and remuneration of mentors, student attendance, and the structure of PASS. The results illustrate how academics and mentors in the sample expressed concern that centralisation would lead to a loss of ownership over schemes. However, these concerns were found to be mitigated by the strengths of co-ownership between academic leads and learning developers, which included the increase in support and the generation of awareness about PASS through existing LD networks.

\section{Advertising and attendance}

Timetabled schemes (medical sciences (2) and arts (4)) appeared to have more stable attendance in the findings. Conversely, those which are not timetabled (humanities (1) and physical science (3)) report less stable attendance overall. Those which are not timetabled appeared to rely on advertising to students through Virtual Learning Environments (VLE), social media, or student emails. Yet attendance remained unstable:

Advertising and getting it out there were the most difficult, it wasn't enough for me to just go on induction day and say something about PASS and please sign up. I would have to sort of guilt my first year into going. That is not ideal, we don't want to have to do that. ${ }^{2}$

According to Meertens (2016) and Allen et al. (2019) unpredictable and low student attendance may also be due to students having the impression that PASS is solely for students who are academically weak. This notion was confirmed by a PASS mentor in the focus group who stated:

I feel like there is a bit of a reputation problem as well because it seems like PAL is only for those who are really struggling, have a $D$ and need the help. I think it would do better if it was marketed as if you have a B, come and try get an $A{ }^{3}$

\footnotetext{
2 Academic Lead for (1).

$3 \mathrm{Jim}$, Pass mentor in (3). 
Despite attempts at advertising and timetabling, attendance continues to be a challenge among the PASS initiative within the humanities (1), physical sciences (3), and the arts (4). As the excerpt above indicates, lower attendance in these areas might be based on a lack of student awareness that a scheme is in place, as well as misconceptions around the purpose of a PASS. Centralised schemes would benefit from wider advertising as LDs are often in contact with a broader range of students.

\section{Mentor training}

The study found that humanities (1) provide an internally-led training day for mentors. On this day, mentors are given practical exercises to develop their facilitation skills. By the end of the training day, the mentors leave with knowledge of the requirements of the role, services for referral, and a rough plan for the first few sessions. Training in the arts (4) and medical sciences (2) was done by staff and previous PASS mentors. The physical sciences (3) did not have formal training for mentors. The focus group indicated that PASS was growing within the school and that additional attention to the mentors through communication and training was desirable. This point was confirmed by the Academic PASS lead in (3) who stated that greater involvement from LDs in PASS would aid training of mentors. These findings illustrate the diversity in training provided by each subject. While subject-specific training is necessary, greater involvement from LDs would build on successful subject-specific training by providing additional material, such as training on facilitation.

\section{Mentor remuneration}

When establishing PASS, the humanities (1) did not pay their mentors but acknowledged their contribution through formal recognition from the principle at a peer support awards ceremony. However, with the awards ceremony no longer occurring, the scheme decided to pay their mentors, as the AL explains: 'There were conversations which we had, and the school then determined that they receive remuneration. Which I think is right in this instance because the degree is highly time consuming'. ${ }^{4}$

\footnotetext{
${ }^{4}$ Academic Lead for (1) 
Alternatively, one academic cautions against monetary remuneration based on unstable funding: 'If you build it on a temporary bit of money and the money goes then the support will go. If you embed it into the culture, then it will be more mainstream and likely to last a bit longer'. 5

The excerpt above highlights how funding and monetary remuneration is a challenge to the sustainability of PASS.

\section{Academic involvement}

Participants stated that support from the wider academic staff team, as well as communication between mentors and staff, were vital for a scheme's success. Equally, all participants stated that this area could be improved. The physical sciences (3) report that staff are aware of, but do not actively promote, PASS. Furthermore, the AL explains that despite attempts to set up regular meetings between mentors and the relevant academics, there was little uptake. Communication continued to be an area for improvement, as one mentor reports: 'I think even just if we had more meetings it would be really beneficial. Some informal supervision and feedback'. ${ }^{6}$

The medical sciences (2) exhibit substantial staff support; this is due to the high level of involvement from staff in developing the scheme, as well as in training the mentors. Mentors in the humanities (1) meet with academics bi-weekly to plan upcoming activities, exchange knowledge, discussing the sessions, and any challenges. Similarly, the arts (4) report strong communication between mentors, who met with the AL once a week for one hour to discuss the scheme and any concerns. Unfortunately, the school also reported that buy-in from other academics within the school was incredibly low. The academic PASS lead reported that without a dedicated member of staff to oversee PASS, the support within the school became 'fractured'. Should staff other than the AL within the subjects not take up involvement with PASS, the additional support from LDs in a co-owned scheme would prove beneficial.

\footnotetext{
5 Academic (1)

6 Sam, PASS mentor in (3). 


\section{Centralisation}

There is always the fear that if it is centralised you will lose some of its flavour and become bureaucratic. We still want to feel as though we run it, we know what our students need. We wouldn't want it taken over or away from us but working in partnership with you. ${ }^{7}$

The excerpt above exemplifies most participants' response to centralisation. When asked if the schools would support a centralised PASS, co-ordinated by learning developers, each school expressed varying degrees of support. The biggest concern was that ALS would lose ownership of the material. This is a reasonable concern when considering the efforts of ALs to develop and maintain PASS. Participants were especially positive regarding the opportunity to have LDs involved in developing mentor training: 'I would say there absolutely is a need for some centralised training, which focuses on the general skills needed for facilitation'. 8

Centralised training would be encouraged to focus on preparing the generic skills needed for facilitation, followed by subject-specific training. It would also inform mentors of the referral services such as learning development, mental health, careers, and disabilities services. Furthermore, this training would enable mentors to create networks of communication and support.

\section{Discussion}

In this appraisal of the varieties of PASS within a single HEl the objective was to investigate: the structure and content of PASS; attendance and ways of advertising; approaches to mentor recruitment, training, and remuneration; academic involvement. These areas were investigated alongside the overarching question of whether a more centralised PASS, developed in co-ownership with learning developers, would mitigate some of the challenges facing the successful development of PASS. As the results above indicate, the question of centralisation was welcomed by academics. Specifically, as it

\footnotetext{
${ }^{7}$ Academic PASS lead for (3).

${ }^{8}$ Academic PASS lead for (1). 
related to support for increasing student awareness of PASS as well as training. The discussion below situates the idea of centralisation within the wider literature and indicates areas in which centralisation may improve challenges associated with PASS such as low attendance, misconceptions of PASS, mentor training, and means of recognition.

\section{Advertising with support of learning development services}

Unstable attendance is a challenge to the success of PASS (Hammond et al., 2010; Meertens, 2016) largely because sessions rely on collaboration and discussion of course work between attendees (Fredriksson et al., 2020). Participants reported that timetable clashes and student misconceptions about PASS were common reasons for low attendance. A means of addressing unstable attendance might be through timetabling sessions as schools which had timetabled sessions reported more stable attendance above. Moreover, greater advertising to address misconceptions that PASS is only for students who are struggling academically could also combat low attendance. These assumptions are in line with the suggestions of Cameron et al. (2015), Meertens (2016), and Allen, et al (2019). Despite the benefits of wider advertising, the findings indicated that timetabling placed an administrative burden on organisers - a resource which was not available to all schools.

The support of LDs, especially relating to advertising, would be a useful resource to help establish successful schemes. This in turn would act to combat unstable attendance as well as to address misconceptions over PASS. The research found participants supporting involvement from LDs in advertising schemes. Due to their networking across the institution and their frequent contact with students, LDs are particularly well placed to present the benefits of PASS along with increasing students' awareness of ongoing sessions. In addition, LDs can support the advertisement of PASS due to their experience of having to communicate that the services they deliver are useful to all students, not just those who are at risk of failure. Dawson, et al. (2017) and Fostier and Carey (2007) stress the importance of advertising strategies to inform that PASS will be helpful to students of diverse ages, academic abilities, and social economic status. When schemes are coowned and developed in partnership between ALs and LDs it means that more time and resources can be dedicated to advertising, thereby working towards greater uptake of PASS to ensure that many students receive the numerous benefits associated with peerto-peer learning. 
Finally, the wider literature indicates that involvement from senior subject academics in promoting PASS has led to students viewing schemes as having legitimacy, making them more likely to attend (Kodabux and Hoolash, 2015). Academics may be able to communicate the overall benefits of PASS but this rests on the assumption that they are aware of these benefits. A centralised service is able to communicate the benefits of PASS to academics through dissemination of information at steering groups and teaching committees, or through practitioner research within the institution. This discussion indicates support for shared ownership of PASS not only within the current sample, but within the wider literature.

\section{Centralised training}

Learning developers' proposal for centralised training of mentors received unanimous support from participants largely due to the high demands of running mentor training. The idea of centralised learning development services being involved in training mentors provides a strong case in the argument for centralisation. Garcia-Melgar et al. (2021) state that the consequences of inadequate training of PASS mentors may lead to mentors who are not able to recognise the need to facilitate, rather than to teach material. This is supported by Ody and Carey (2009) and Capstick, Fleming and Hurne (2004) who also reported that a major challenge of PASS mentorship was that mentors tended to move to teaching rather than facilitating sessions due to inadequate training. Moreover, inadequate training, which often results from academics not having enough time and resources to adequately train mentors, can also lead to mentors being unable to assert appropriate boundaries, and a lack of awareness of the necessary channels of referral - such as counselling, academic, or financial services (Garcia-Melgar et al., 2021). Conversely, training which provides mentors with knowledge over the function of their role, as well as increasing their knowledge of services, had the additional benefit of developing schemes which 'scaffolded and supported pathways to effective help-seeing' (Garcia-Melgar et al., 2021, p.11). It is therefore clear that adequate training of PASS mentors is vital to the overall success and quality control of schemes (Hermann-Werner, 2017). Centralised training might also be supported due to a recognition of the expertise offered by LDs in areas of learning and teaching. LDs may draw on insights from scholarship to provide mentors with best practice resources for facilitating PASS sessions. 
Centralised training, developed by learning developers and subject academics may provide a stronger foundation for schemes than subject-only training. Should training be undertaken through a centralised service, it would be specific to excellence in PASS mentorship in addition to subject-specific training. It would also lead to the development of material which addressed the subject needs and academic literacies. In their study, Garcia-Melgar et al., (2021) found that sessions lacked support for students' academic literacy needs. It is evident that due to the expertise which learning developers hold, their involvement in training and setting up of PASS schemes would make a vital contribution to the content of sessions. Following the example of the University of Bournemouth's centralised PAL project (Capstick and Fleming, 2001) the involvement of LDs in training might also extend to refresher sessions, resources on VLEs, and PASS development workshops for academic staff.

\section{Mentor remuneration}

Wadoodi and Crosby (2002) state that some form of mentor remuneration is required: this may take the form of 'intrinsic or extrinsic reward' (p.242). My research found that each school recognised and promoted both the intrinsic and career benefits associated with PASS mentorship. However, the schools expressed confusion over which was the most sustainable option. Learning developers, who have an understanding of matters relating to learning and teaching and peer assisted schemes, would be able to provide guidance for schools which are creating a PASS.

Academics also expressed a desire to recognise the work of their mentors alongside an inability to arrange areas for mentors to receive recognition such as formally tracking their teaching experience through higher education academic records. One academic explained how the PAL awards ceremony was previously well received by mentors as a form of recognition, but that the school was unable to organise this. A centralised service might contribute to the recognition of the service of mentors by arranging PASS awards ceremonies. The organisation of such an event might not be appealing to academics who are involved in PASS within a single subject. However, the position of the learning developer within higher education translates to wider networks and a greater awareness of learning support being offered across an institution. An event such as this would act to promote the benefits of PASS to the wider student body. 


\section{Examples of Centralisation}

As we have noted, centralised schemes, managed by LDs or PAL co-ordinators in partnership with subjects, is not a new approach, and has received support both in UKHEI and scholarly literature (Makala, 2017). McCabe and Daudi (2018) presented discussions of centralised services which developed each scheme in co-ownership with academic leads and learning developers. The service oversaw recruitment and training of mentors, continued development, and quality enhancement by supporting any problems experienced by the schools. Similarly, Capstick and Fleming (2001) report that at Bournemouth University, peer assisted schemes are successfully managed through a centralised 'pal project' wherein LDs oversee training of PASS mentors, staff development, advertising to students, and research into the improvement of peer learning schemes within the university (Bournemouth University, 2021). However, despite the objective value of centralisation, the current research indicated that some ALs have reservations centred around fears about a loss of ownership. Thus, it is vital that more literature is offered to present the benefits of centralisation to academics interested in peer-to-peer student learning. The current article presents an important consideration of centralisation: its emphasis is on collaboration and ownership between learning developers and academics, rather than one body holding sole ownership.

The findings here, of course, pertain to a single UK institutional case study and are not considered to be representative. However, the findings also uphold what other researchers have observed regarding the training of mentors (Hermann-Werner et al., 2017), low attendance (Hammond et al., 2010), misconceptions of PASS (Kodabux and Hoolash, 2015; Allen et al., 2019) and the need for greater institutional support (Makala, 2017). In focusing on PASS across an institution, rather than within a single subject, this study cannot claim to offer any significant trends in subject/disciplinary PASS. Yet by focusing on a range of subject schemes, it has foregrounded centralisation as a solution to common challenges.

\section{Conclusion}

This article outlined the academic and cultural benefits that PASS brings to an institution. It has also presented how a centralised service responsible for supporting the creation and 
maintenance of PASS, with a specific role in the training of PASS mentors within an institution, would be beneficial. Specially, through advertising and greater exposure, it would work to combat low attendance and incorrect assumptions of PASS. Vitally, a PASS co-owned with academics and learning developers can provide additional training and certifications for mentors. Finally, the current article stressed that any centralisation of PASS should be done in a spirit of partnership, maintaining flexibility, and allowing each PASS to be designed according to the needs of each school.

\section{References}

Allen, P. J., Tonta, K. E., Haywood, S. B., Pereira, R. M. and Roberts, L. D. (2019) 'Predicting peer-assisted study session attendance', Active Learning in Higher Education, 20(3), pp.249-262. https://doi.org/10.1177/1469787417735613.

Ashwin, P. (2002) 'Implementing peer learning across organisations: the development of a model', Mentoring and Tutoring, 10(3), pp.221-231. https://doi.org/10.1080/1361126022000037051.

Black, F.M. and MacKenzie, J. (2008) Peer support in the first year. Available at https://www.enhancementthemes.ac.uk/docs/ethemes/the-first-year/peer-supportin-the-first-year.pdf?sfvrsn=2562f981 8 (Accessed: 11 October 2016).

Bournemouth University (2021) Peer support leader guide. Available at: https://libguides.bournemouth.ac.uk/peersupport (Accessed: 3 March 2021).

Braun, V. and Clarke, V. (2006) 'Using thematic analysis in psychology', Qualitative Research in Psychology, 3(2), pp.77-101.

Cameron, D. A., Binnie, V. I., Sherriff, A. and Bissell, V. (2015) 'Peer assisted learning: teaching dental skills and enhancing graduate attributes', British Dental Journal, 219(6), pp.267-272. https://doi.org/10.1038/sj.bdj.2015.722.

Capstick, S. (2004) 'Benefits and shortcomings of peer assisted learning (PAL) in higher education: an appraisal by students', Peer Assisted Learning Conference 
Proceedings. Bournemouth University, UK January. Available at:

https://www.bournemouth.ac.uk/sites/default/files/asset/document/stuartcapstick.pdf (Accessed: 16 June 2021).

Capstick, S. and Fleming, H. (2001) 'Peer Assisted Learning in an undergraduate hospitality course: second year students supporting first year students in group learning', Journal of Hospitality, Leisure, Sport \& Tourism Education, 1(1), pp.69-75.

Capstick S., Fleming, H., and Hurne, J. (2004) 'Implementing Peer Assisted Learning in higher education: the experience of a new university and a model for the achievement of a mainstream programme', Peer Assisted Learning Conference Proceedings. Bournemouth University, UK January. Available at: https://www.bournemouth.ac.uk/sites/default/files/asset/document/capstick-fleminghurne.pdf (Accessed: 16 June 2021).

Chilvers, L. (2016) 'Communities of practice for international students: an exploration of the role of Peer Assisted Study Sessions in supporting transition and learning in higher education', Journal of Learning Development in Higher Education, Special Edition, April, pp.1-25. https://doi.org/10.47408/jldhe.v0i0.366.

Congos, D. H. and Schoeps, N. (1998) 'Inside supplemental instruction sessions: one model of what happens that improves grades and retention', Research and Teaching in Developmental Education, 15(1), pp.47-61.

Dawson, P., van der Meer, J., Skalicky, J. and Cowley, K. (2014) 'On the effectiveness of supplemental instruction: a systematic review of supplemental instruction and peerassisted study sessions literature between 2001 and 2010', Review of Educational Research, 84(4), pp.609-639. https://doi.org/10.3102/0034654314540007.

Draper, S.W. (2011) Peer Assisted Learning. Available at: https://www.psy.gla.ac.uk/ steve/localed/pal.html (Accessed: 6 February 2018).

Duah, F., Croft, T. and Inglis, M. (2014) 'Can peer assisted learning be effective in undergraduate mathematics?', International Journal of Mathematical Education in 
Science and Technology, 45(4), pp.552-565.

https://doi.org/10.1080/0020739X.2013.855329.

Fostier, M. and Carey, W. (2007) 'Exploration, experience and evaluation: Peer Assisted Study Scheme (PASS), sharing the experience of the University of Manchester: 480 1st year bioscience students', Science, Learning and Teaching Conference, Manchester 10 June, pp.19-20. Available at https://www.advancehe.ac.uk/knowledge-hub/exploration-experience-and-evaluation-peer-assistedstudy-scheme-pass-sharing (Accessed: 11 October 2016).

Fredriksson, J., Malm, J., Holmer, A. and Ouattara, L. (2020) 'Attendance numbers at SI sessions and their effect on learning conditions', Journal of Peer Learning, 13(3), pp.21-35.

Garcia-Melgar, A., East, J. and Meyers, N. (2021) 'Peer assisted academic support: a comparison of mentors' and mentees' experiences of a drop-in programme', Journal of Further and Higher Education, pp.1-14. https://doi.org/10.23918/ijsses.v8i3p55.

Glynn, L. G., MacFarlane, A., Kelly, M., Cantillon, P. and Murphy, A. W. (2006) 'Helping each other to learn-a process evaluation of peer assisted learning', BMC Medical Education, 6(1), pp.1-9.

Green, J. L. (2018) 'Peer support systems and professional identity of student nurses undertaking a UK learning disability nursing programme', Nurse Education in Practice, 30, pp.56-61. https://doi.org/10.1016/j.nepr.2017.11.009.

Green, P. (2011) 'A literature review of peer assisted learning (PAL)', National HE STEM. Available at: http://projects.hestemsw.org.uk/upload/Literature review 26.1.11 Green-1.pdf (Accessed: 28 September 2021).

Hammond, J. A., Bithell, C. P., Jones, L. and Bidgood, P. (2010) 'A first year experience of student-directed peer-assisted learning', Active Learning in Higher Education, 11(3), pp.201-212. https://doi.org/10.1177/1469787410379683. 
Herrmann-Werner, A., Gramer, R., Erschens, R., Nikendei, C., Wosnik, A., Griewatz, J., Zipfel, S. and Junne, F. (2017) 'Peer-assisted learning (PAL) in undergraduate medical education: an overview', Zeitschrift für Evidenz, Fortbildung und Qualität im Gesundheitswesen, 121, pp.74-81. https://doi.org/10.1016/j.zefq.2017.01.001.

Higgins, D., Dennis, A., Stoddard, A., Maier, A. G. and Howitt, S. (2019) "'Power to empower": conceptions of teaching and learning in a pedagogical co-design partnership', Higher Education Research \& Development, 38(6), pp.1154-1167. https://doi.org/10.1080/07294360.2019.1621270.

Hoffman, M., Richmond, J., Morrow, J. and Salomone, K. (2002) 'Investigating "sense of belonging" in first-year college students', Journal of College Student Retention: Research, Theory \& Practice, 4(3), pp.227-256. https://doi.org/10.2190/DRYCCXQ9-JQ8V-HT4V.

Kodabux, A. and Hoolash, B. K. A. (2015) 'Peer learning strategies: acknowledging lecturers' concerns of the Student Learning Assistant scheme on a new higher education campus', Journal of Peer Learning, 8(1), pp.59-84.

Makala, Q. (2017) 'Peer-assisted learning programme: supporting students in high-risk subjects at the Mechanical Engineering Department at Walter Sisulu University', Journal of Student Affairs in Africa, 5(2), pp.17-31. https://doi.org/10.24085/jsaa.v5i2.2700.

Maccabe, R. and Daudi, H. (2018) 'The good, the bad, the ugly: students co-producing learning, past, present and future', SEDA Staff and Educational Development Association. Available at: https://www.seda.ac.uk/resources/files/Rebecca\%20Maccabe\%20and\%20Hinna\%2 ODuadi\%20SEDA\%20Final.pdf (Accessed: 28 September 2021).

Mclntosh, E. A. (2019) 'Working in partnership: the role of Peer Assisted Study Sessions in engaging the citizen scholar', Active Learning in Higher Education, 20(3), pp.233248. https://doi.org/10.1177/1469787417735608. 
Meertens, R. (2016) 'Utilisation of a peer assisted learning scheme in an undergraduate diagnostic radiography module', Radiography, 22(1), pp.e69-e74. https://doi.org/10.1016/j.radi.2015.08.004.

Ody, M. and Carey, W. (2009) 'Demystifying peer assisted study sessions (PASS): What...? How...? Who...? Why.... Why', The Challenge of Learning Development., 6th LDHEN symposium. Bournemouth. Available at: https://documents.manchester.ac.uk/display.aspx?DoclD=7418 (Accessed: 12 March 2019).

Ody, M. and Carey, W. (2013) 'Peer education', in Dunne, E. and Owen, D. (eds.) Student engagement handbook: practice in higher education. Bingley: Emerald Group Publishing Limited, pp.291-312.

PASS National Centre (2018) UK National PASS Network. Available at: http://www.pass.manchester.ac.uk/uk-national-pass-network/ (Accessed: 12 March 2018).

Rapley, E. (2011) "“I get by with a little help from my friends”: peer assisted learning', Journal of Pedagogic Development, 1(1), pp.16-19.

Smith, J., May, S. and Burke, L. (2007) 'Peer Assisted Learning: a case study into the value to student mentors and mentees', Practice and Evidence of the Scholarship of Teaching and Learning in Higher Education, pp.80-109. https://doi.org/10.3102/0034654314540007.

Spedding, J., Hawkes, A. J. and Burgess, M. (2017) 'Peer assisted study sessions and student performance: the role of academic engagement, student identity, and statistics self-efficacy', Psychology Learning \& Teaching, 16(1), pp.144-163. https://doi.org/10.1177/1475725716687166.

Tibingana-Ahimbisibwe, B., Willis, S., Catherall, S., Butler, F. and Harrison, R. (2020) 'A systematic review of peer-assisted learning in fully online higher education distance learning programmes', Open Learning: The Journal of Open, Distance and eLearning, pp.1-22. https://doi.org/10.1080/02680513.2020.1758651. 
Tamachi, S., Giles, J. A., Dornan, T. and Hill, E. J. (2018) "'You understand that whole big situation they're in": interpretative phenomenological analysis of peer-assisted learning', BMC Medical Education, 18(1), pp.1-8.

Wadoodi, A. and Crosby, J. R. (2002) 'Twelve tips for peer-assisted learning: a classic concept revisited', Medical Teacher, 24(3), pp.241-244. https://doi.org/10.1080/01421590220134060.

Zaccagnini, M. and Verenikina, I. (2013) 'Peer assisted study sessions for postgraduate international students in Australia', Journal of Peer Learning, 6(1), p.8.

\section{Author details}

Maxinne Connolly-Panagopoulos is a lecturer in Psychology at the University of Highlands and Islands and an associate tutor in Psychology at the University of Glasgow. She has also worked as an effective learning advisor at the University of Glasgow. Her research largely focuses on the Psychology of Religion, but she also conducts research into student identity and belonging. 